\title{
Surface Characteristics and High Cycle Fatigue Performance of Shot Peened Magnesium Alloy ZK60
}

\author{
Jie Dong, ${ }^{1}$ Wencai Liu, ${ }^{1}$ Wenjiang Ding, ${ }^{1,2}$ and Jianxin Zou ${ }^{1}$ \\ ${ }^{1}$ National Engineering Research Center of Light Alloy Net Forming, School of Materials Science and Engineering, \\ Shanghai Jiao Tong University, Shanghai 200240, China \\ ${ }^{2}$ Key State Laboratory of Metal Matrix Composite, School of Materials Science and Engineering, Shanghai Jiao Tong University, \\ Shanghai 200240, China \\ Correspondence should be addressed to Jie Dong, jiedong@sjtu.edu.cn
}

Received 28 January 2011; Accepted 26 April 2011

Academic Editor: Thierry Grosdidier

Copyright () 2011 Jie Dong et al. This is an open access article distributed under the Creative Commons Attribution License, which permits unrestricted use, distribution, and reproduction in any medium, provided the original work is properly cited.

The current work investigated the effect of shot peening (SP) on high cycle fatigue (HCF) behavior of the hot-extruded ZK60 magnesium alloy. SP can significantly improve the fatigue life of the ZK60 alloy. After SP at the optimum Almen intensities, the fatigue strength at $10^{7}$ cycles in the as-extruded (referred to as ZK60) and the T5 aging-treated (referred to as ZK60-T5) alloys increased from 140 and $150 \mathrm{MPa}$ to 180 and $195 \mathrm{MPa}$, respectively. SP led to a subsurface fatigue crack nucleation in both ZK60 and ZK60-T5 alloys. The mechanism by which the compressive residual stress induced by shot peening results in the improvement of fatigue performance for ZK60 and ZK60-T5 alloys was discussed.

\section{Introduction}

The weight reduction of automobiles is one of the most effective ways to improve fuel consumption since the resistance of a vehicle to rolling, climbing, and acceleration are directly dependent on the vehicle mass. Therefore, the application of magnesium alloys which have the density only roughly $25 \%$ of that of steel and $66 \%$ of that of aluminum is expected to increase substantially in this decade $[1,2]$. For these automotive components under the combined actions of fluctuating loads and corrosive environment, good high cycle fatigue (HCF) performance must be achieved. However, in comparison to aluminum alloys and steels, the research results on fatigue properties of magnesium alloys are still limited. Some research has shown that the fatigue properties of magnesium alloys are poor $[3,4]$, thus making it difficult to apply the alloys for load-bearing parts in automobiles. Therefore, the improvement of the fatigue properties of magnesium alloys becomes a vital research subject.

Considering the fact that crack initiation of magnesium alloy is a surface phenomenon controlled by aspects as residual stress level near the surface, the existence of compressive residual stresses in surface region results in an improvement of fatigue properties $[5,6]$. Shot peening $(\mathrm{SP})$ is a powerful method to enhance the fatigue performance of structural metallic materials, and some investigations on the influence of shot peening were performed on the $\mathrm{Mg}-\mathrm{Al}$ alloys $\mathrm{AZ31}$, AZ80 $[7,8]$, and A8 $[9]$. The results demonstrated that SP effectively improved the fatigue properties of magnesium alloys [7-9]. However, bombardment of the surface with the shot often leads to the initiation of flaws or cracks, whose detrimental effect on strength may outweigh the beneficial effect of the compressive residual stresses. Thus, for magnesium alloys, care must be taken to optimize the peening conditions. This requires a detailed investigation of the microprocesses associated with SP.

The wrought magnesium alloy, ZK60, has the excellent ductility and the highest strength among commercial magnesium alloys [10]. Its microstructure, mechanical properties, deformation treatment, and the effects of the alloying elements and microelements are well studied [11]. At present, research on the ZK60 alloy is mainly focused on the plasticity, superplasticity, and ZK60-based composites [12, 13]. However, the main limitations to the application of ZK60 alloy in the automotive industry are its comparatively poor fatigue properties and wear resistance $[14,15]$. Therefore, 


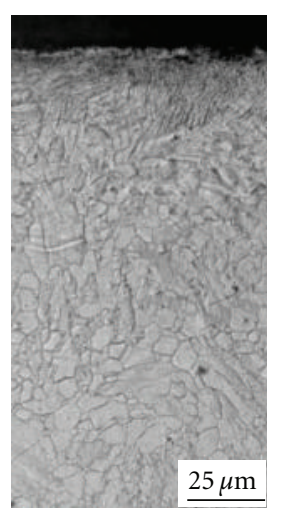

(a)

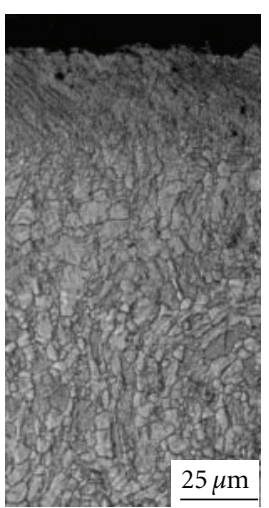

(b)

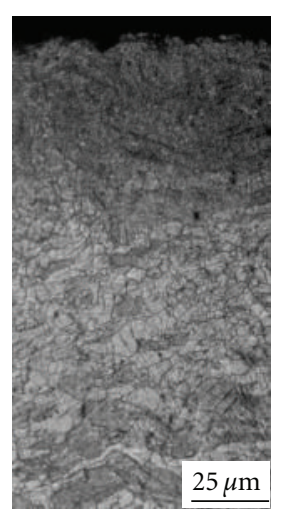

(c)

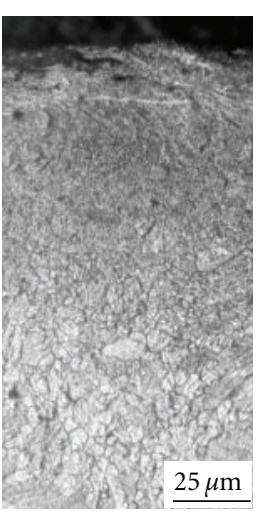

(d)

FIgURE 1: Section topographies of the peened ZK60 alloy at different Almen intensities: (a) $0.05 \mathrm{mmN}$; (b) $0.10 \mathrm{mmN}$; (c) $0.30 \mathrm{mmN}$; (d) $0.40 \mathrm{mmN}$.

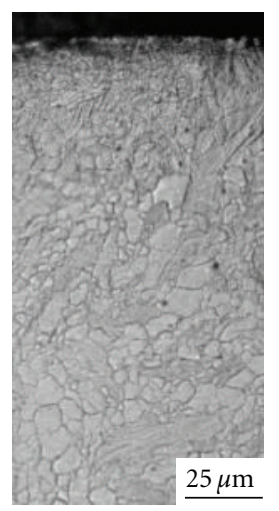

(a)

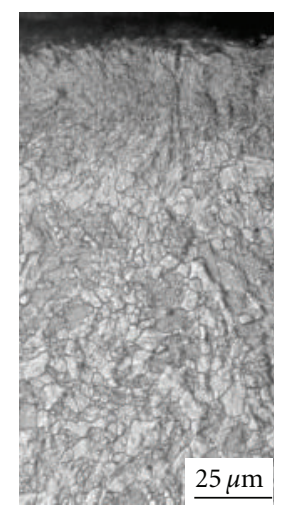

(b)

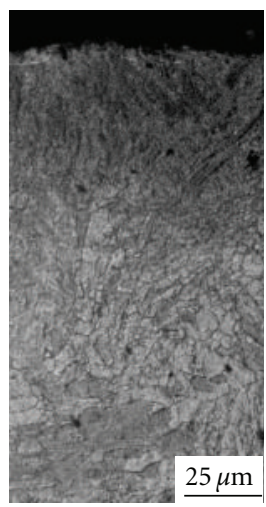

(c)

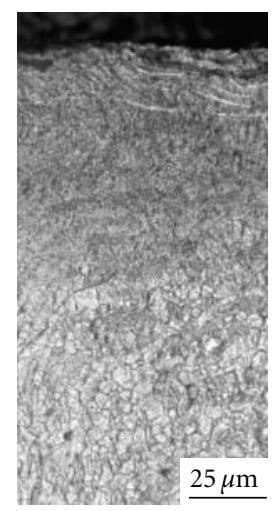

(d)

Figure 2: Section topographies of the peened ZK60-T5 alloy at different Almen intensities: (a) $0.05 \mathrm{mmN}$; (b) $0.10 \mathrm{mmN}$; (c) $0.30 \mathrm{mmN}$; (d) $0.40 \mathrm{mmN}$.

the present work aims at investigating the possibility of using SP to improve the fatigue properties of hot-extruded ZK60 alloy and hot-extruded plus T5 aging-treated ZK60 alloy (referred to as ZK60-T5).

\section{Experimental}

The hot-extruded magnesium alloy ZK60 (nominal composition in wt.\%: 5-6 Zn, 0.3-0.9 Zr, balance $\mathrm{Mg}$ ) was used in this study and had the chemical composition Mg-5.54Zn$0.56 \mathrm{Zr}$ (wt.\%) [16, 17]. The extrusion ratio of about 14 was applied to produce the extruded bar with external diameter of $26.8 \mathrm{~mm}$. Peak aging $\left(\mathrm{T} 5,150^{\circ} \mathrm{C} / 24 \mathrm{~h}\right)$ was applied to some of the hot-extruded cylindrical bars, referred to below as ZK60-T5.

The phase composition analyses of the ZK60 and ZK60T5 alloys can be found in [16]. The ZK60 alloy mainly consists of $\alpha-\mathrm{Mg}$ and $\mathrm{MgZn}_{2}$, and $\mathrm{MgZn}$ precipitates were present besides $\alpha$-Mg and $\mathrm{MgZn}_{2}$ in the ZK60-T5 alloy.

Tensile properties of ZK60 and ZK60-T5 alloys were determined using sheet specimens with the marked dimensions of $15-\mathrm{mm}$ gauge length, $3.6-\mathrm{mm}$ width, and $2-\mathrm{mm}$ thickness on the Zwick/Roell Z020 (A.S.T. GmbH, Dresden, Germany) tensile testing machine at room temperature. The initial strain rate was $5 \times 10^{-4} \mathrm{~s}^{-1}$. The yield strength, the ultimate tensile strength, and the elongation increased from $237 \mathrm{MPa}, 312 \mathrm{MPa}$, and $15.5 \%$ to $273 \mathrm{MPa}, 329 \mathrm{MPa}$, and $16.5 \%$ after $\mathrm{T} 5$ aging treatment, respectively. The tensile properties of ZK60 and ZK60-T5 alloys were described in detail elsewhere [16].

The hour-glass shaped round fatigue specimens $(6 \mathrm{~mm}$ gauge diameter) were used for the fatigue tests. After machining, a layer with thickness of about $200 \mu \mathrm{m}$ was removed from the specimen surface by electrolytically polishing (EP) in order to avoid the influence of machining on the fatigue results. Shot peening (SP) was performed with an injector type machine using glass beads (average shot size $0.35 \mathrm{~mm}$ and Rockwell hardness 48 (HRC)). During the peening treatment, the specimens rotated at $1 \mathrm{~s}^{-1}$. The distance between the nozzle tip and the specimen surface was about $100 \mathrm{~mm}$. To determine the optimum SP condition with regard to HCF properties, specimens were shot peened to full coverage by using Almen intensities in the range of 0.02 $0.60 \mathrm{mmN}$. Fatigue tests were performed under a rotating beam loading $(R=-1)$ at a frequency of $100 \mathrm{~Hz}$ in air. 


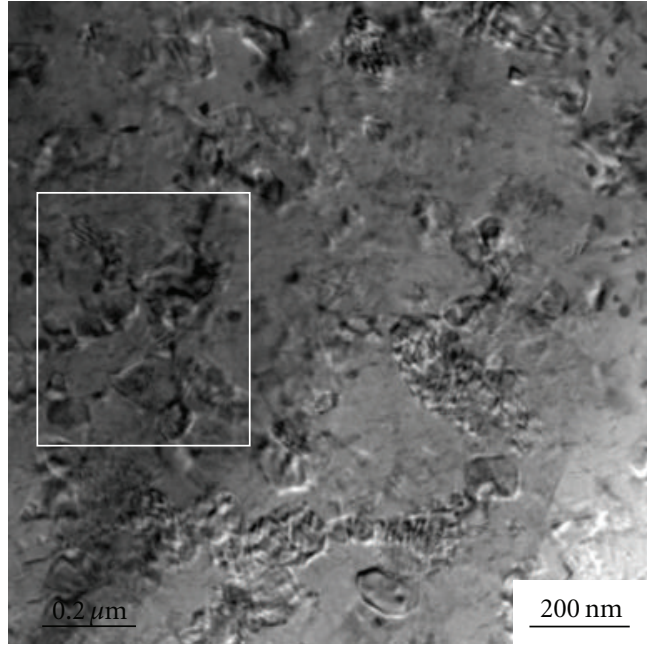

(a)

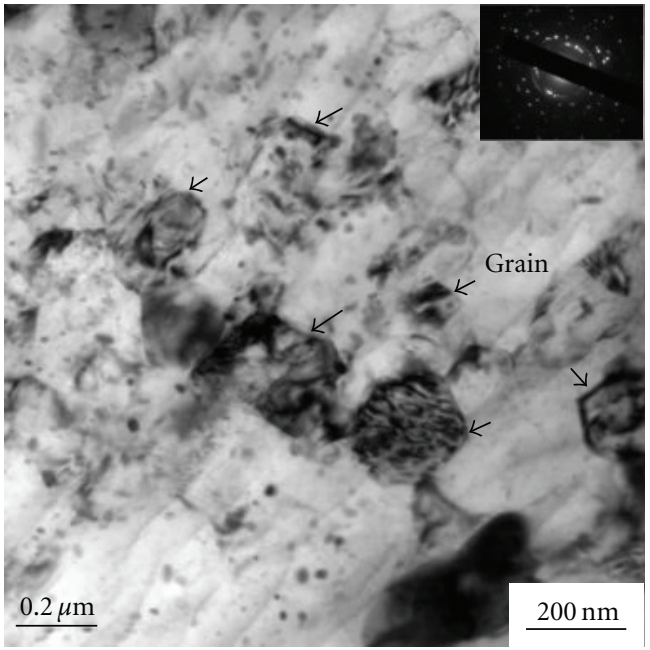

(c)

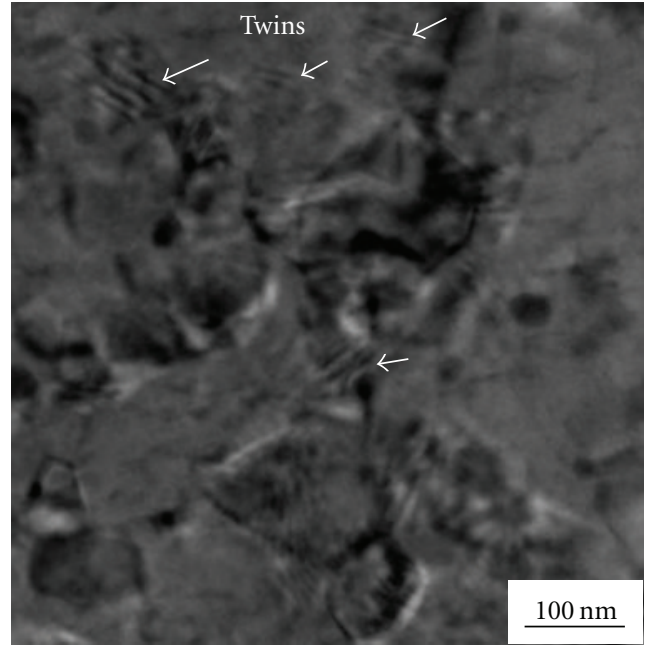

(b)

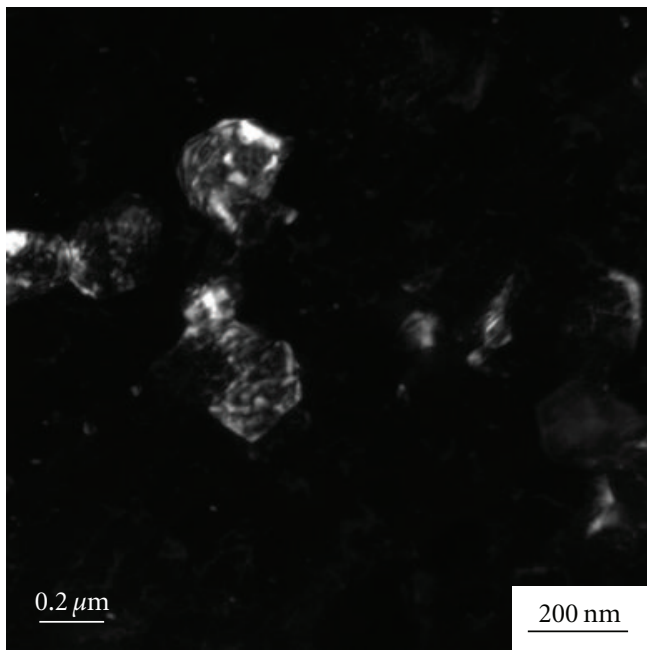

(d)

FIgURE 3: TEM images and corresponding SAED patterns of ZK60 alloy after SP at Almen intensity of 0.10 mmN: (a) bright field image and (b) its magnification about $10 \mu \mathrm{m}$ depth; (c) bright field image and SAED pattern as well as (d) its dark field image about $20 \mu \mathrm{m}$ depth.

The surface properties of the peened specimens were determined by roughness measurements using profilometry, measurements of the microhardness/depth profiles, and residual stress measurements by means of a successive surface layer removal from the top of the peened specimen [18]. The microstructures of EP and peened specimens were observed by optical microscope (OM) and JEM-2010 (TEM, JEOL, Tokyo, Japan) transmission electron microscope. The fracture surfaces after fatigue failure were analyzed using scanning electron microscopy (SEM, Philips-505, Holland).

\section{Results}

3.1. Microstructure. The detailed analysis on the microstructures of ZK60 and ZK60-T5 in the plane parallel to the extrusion direction (ED) can be found in [16]. The microstructures of the ZK60 alloy (and the ZK60-T5 alloy) consist of bands of compounds A, B, and C (and compounds A and
D) that are characteristic of deformation structure. These regions appear as parallel layers and indicate the deformation flow lines. These compounds A, B, and C in ZK60 alloy are $95.5 \mathrm{Mg}-3.4 \mathrm{Zn}-1.1 \mathrm{Zr}$ (at.\%, primary $\alpha-\mathrm{Mg}$ ), $89.8 \mathrm{Mg}-8.9 \mathrm{Zn}$ $1.3 \mathrm{Zr}$ (at.\%), intermetallic phase of $64.1 \mathrm{Mg}-29.3 \mathrm{Zn}-6.3 \mathrm{Zr}$ (at.\%), and $\alpha-\mathrm{Mg}$, respectively. Average layer dimensions of the compounds, $W_{\mathrm{A}}, W_{\mathrm{B}}$, and $W_{\mathrm{C}}$, are 22,9 , and $16 \mu \mathrm{m}$, respectively, where $W_{\mathrm{A}}, W_{\mathrm{B}}$, and $W_{\mathrm{C}}$ are widths of the $\mathrm{A}, \mathrm{B}$, and $C$ compounds, respectively. The microhardness values for the compounds A, B, and C in ZK60 alloy are 75, 79, and $68 \mathrm{Hv} 0.1$, respectively. However, banded microstructures of ZK60 alloy are not clearly defined after T5 aging treatment, and its $\mathrm{A}$ and $\mathrm{D}$ compounds are $95.5 \mathrm{Mg}-3.4 \mathrm{Zn}-1.1 \mathrm{Zr}$ (at.\%, primary $\alpha-\mathrm{Mg}$ ) and intermetallic phase of $54.8 \mathrm{Mg}-35.5 \mathrm{Zn}-$ $9.7 \mathrm{Zr}$ (at.\%) and $\alpha-\mathrm{Mg}$, respectively [16]. The microhardness values for compounds A and D in ZK60-T5 alloy are 80 and $73 \mathrm{Hv} 0.1$, respectively, that is, slightly higher than those of ZK60 alloy. 


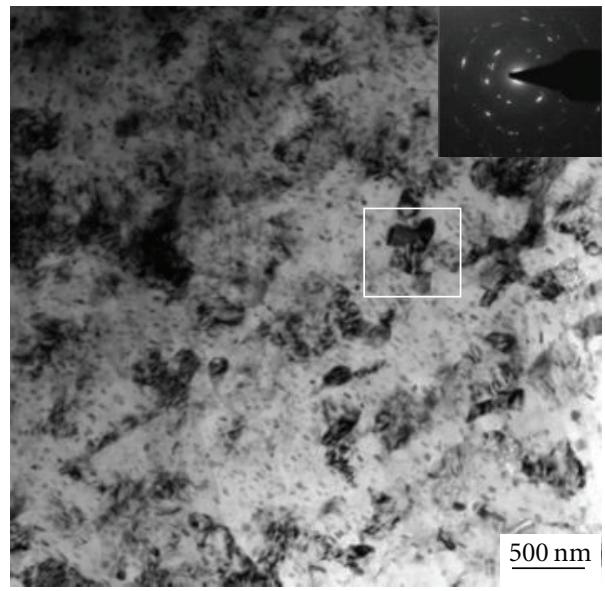

(a)

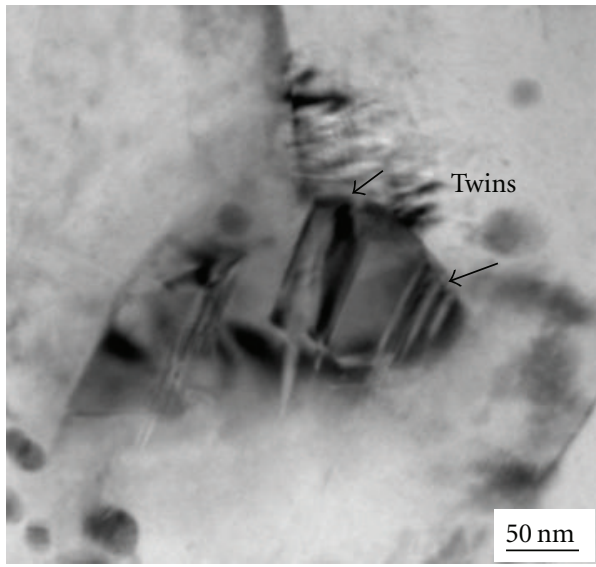

(c)

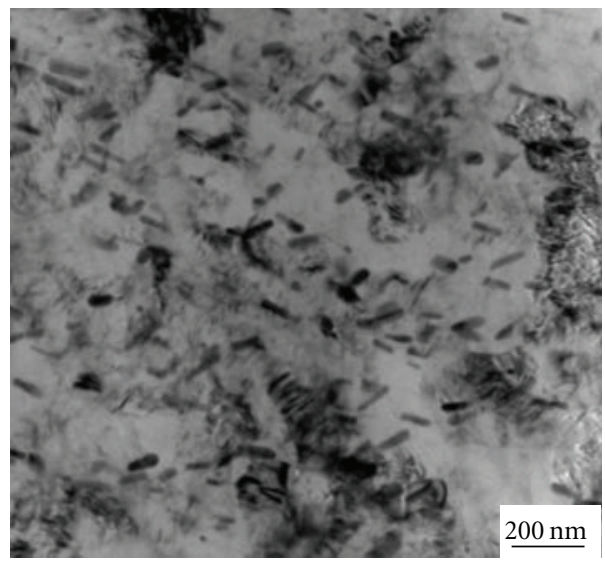

(e)

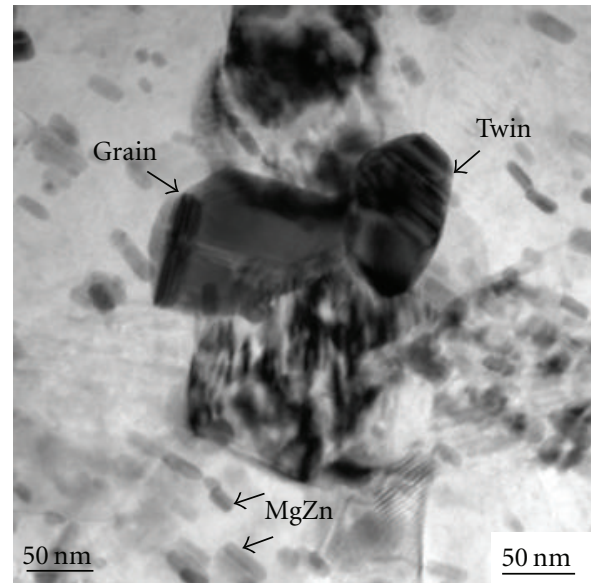

(b)

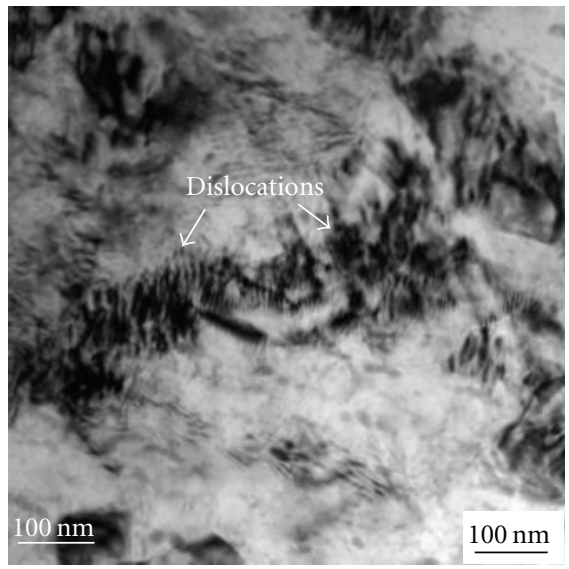

(d)

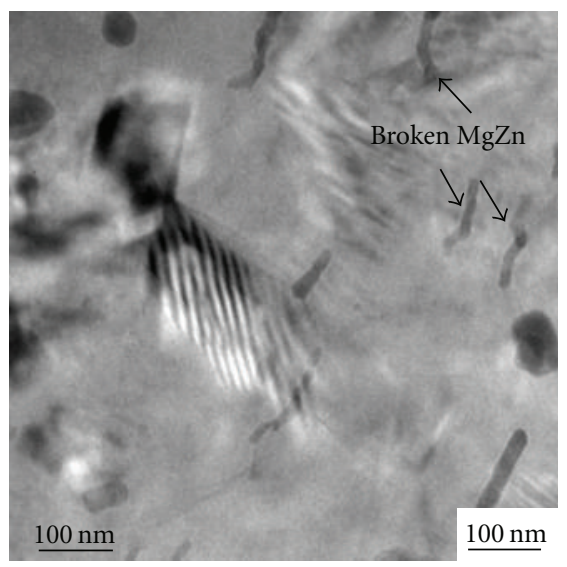

(f)

FIgURE 4: TEM images and corresponding SAED patterns in deformation layer about $10 \mu \mathrm{m}$ depth of ZK60-T5 alloy after SP at Almen intensity of $0.10 \mathrm{mmN}$ : (a) bright field image and (b) its magnification; (c) twin; (d) dislocation; (e) and (f) precipitates.

The microstructures of cross-section of the peened ZK60 and ZK60-T5 alloys at different Almen intensities are shown in Figures 1 and 2, respectively. As seen from Figures 1 and 2, compared to the matrix in ZK60 and ZK60-T5, the grains of deformation layers of peened ZK60 and ZK60-T5 alloys break up and grain boundaries are poorly defined because of dislocation movement and incomplete recrystallization. In addition, it can be seen that the increase in Almen intensity does not significantly change the grain size of the surface layer but increases the thickness of plastic deformation layer.

Figures 3 and 4 show the TEM micrographs of the surface layers of the ZK60 and ZK60-T5 alloys after SP at the Almen intensity of $0.10 \mathrm{mmN}$. From the bright field image (see Figures 3(a), 3(c), and 4(a)), one can see that the grain 


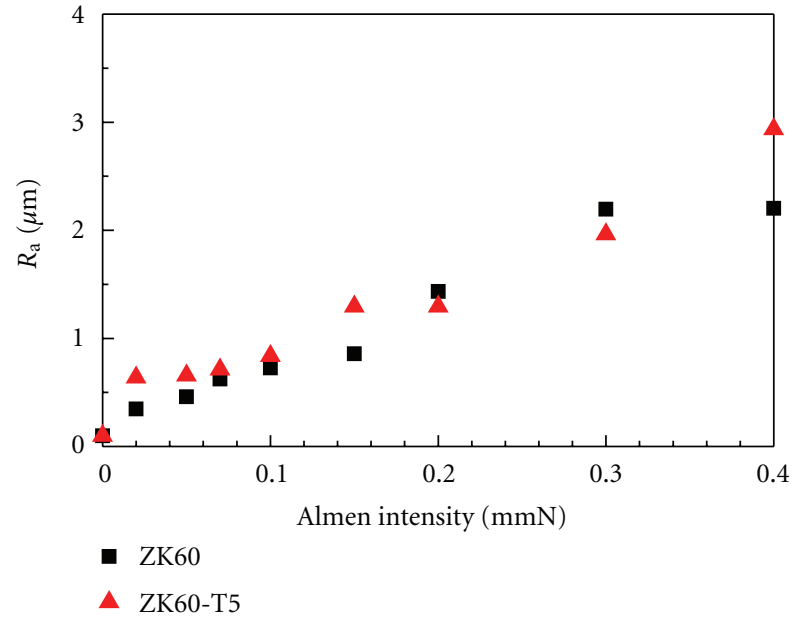

FIGURE 5: Surface roughness values versus Almen intensities.

shape is roughly equiaxed. These grains possess random crystallographic orientations, as indicated in the selected area electron diffraction (SAED) patterns. This TEM investigation indicates that the peened surface region is clearly refined. Meanwhile, TEM observations in Figure 3 indicated that the grain size evidently increased with an increment of the distance from the peened surface. The grains in Figure 3(c) (about $20 \mu \mathrm{m}$ depth) are much larger than those in Figure 3(a) (about $10 \mu \mathrm{m}$ depth).

3.2. Surface Characteristics after SP. Figure 5 shows the surface roughness $R_{\mathrm{a}}$ of the ZK60 and ZK60-T5 alloys at different Almen intensities. SP leads to a linear increase in the surface roughness with Almen intensity compared to the EP condition. In addition, T5 aging treatment seems to have tiny influence on the surface roughness.

Figure 6 shows the microhardness-depth profile after SP with different Almen intensities from 0.02 to $0.40 \mathrm{mmN}$. Owing to SP-induced plastic deformation, there is a significant increase in microhardness in the near-surface region. Increasing the Almen intensity from 0.02 to $0.40 \mathrm{mmN}$ leads to greater depths of plastic deformation. As is well known, the increase in microhardness directly affects the fatigue strength of the tested alloys.

Figure 7(a) shows the residual stress distribution in ZK60 and ZK60-T5 alloys after SP. It can be seen that the SP induced compressive residual stresses. The maximum compressive residual stress increases with the increase in the Almen intensity. For the same Almen intensity, the depth of the compressive zones is similar for the two alloys. However, increasing the Almen intensity also leads to the surface quality loss. The maximum compressive stresses of $54-71 \mathrm{MPa}$ for ZK60 alloy (or 55-76 MPa for ZK60-T5 alloy) are about $55-80 \mu \mathrm{m}$ (or 55-90 $\mu \mathrm{m}$ ) below surface for the Almen intensities of 0.05 and $0.10 \mathrm{mmN}$.

In addition, compared to ZK60 alloy, the slightly higher microhardness and compressive residual stress for ZK60-T5 alloy are probably a consequence of the thicker and more intensively deformed surface skin, which has to be elastically restrained by the subsurface material.

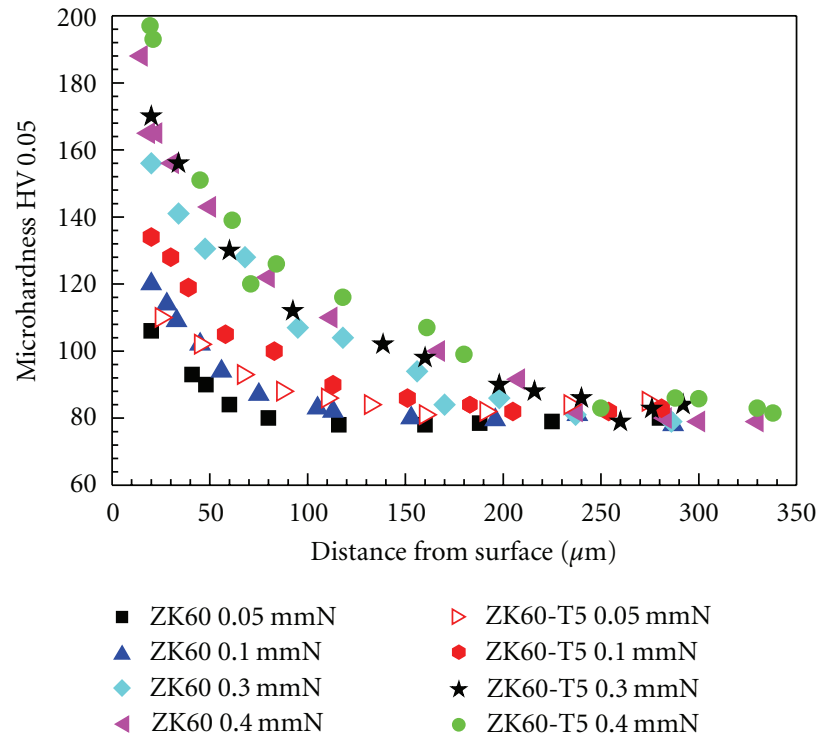

FIGURE 6: Microhardness-depth profile of the peened ZK60 and ZK60-T5 alloys.

However, relaxation of the residual stress induced by SP has been observed over the fatigue cycle (see Figure 7(b)); this may be due to the interaction of the applied loading with the residual stress field causing some shakedown of the residual stress. The samples that were fatigued following peening were subjected to cyclic loading with applied peak stress of $220 \mathrm{MPa}$ after about $6 \times 10^{4}$ cycles of both ZK60 and ZK60-T5 alloys. As seen from Figure 7(b), the compressive residual stress of the peened ZK60 alloy relaxed slightly more rapidly than that of the peened ZK60-T5 alloy leading to lower fatigue lives.

3.3. High Cycle Fatigue. Figure 8 shows the fatigue life as a function of Almen intensity for the ZK60 and ZK60-T5 alloys at different stress amplitudes. Compared to the reference specimens (EP), the fatigue life of the peened specimens is improved by SP. One can see that the fatigue life depends on the Almen intensity at all tested stress amplitudes, especially at the low stress amplitude; the dependence is more evident, that is, the fatigue life first dramatically increased with the increase in the Almen intensity, then decreased drastically as the Almen intensity further increased. Obviously, the significant increase in surface defects such as microcracks and surface spalls at higher Almen intensities outweigh the beneficial effects produced by work hardening and compressive residual stresses [18]. The sensitive response of the magnesium alloys to Almen intensity can be explained by the limit deformability of magnesium alloys at room temperature. With regard to the fatigue performance, the optimum Almen intensities of the ZK60 and ZK60-T5 alloys are all $0.05 \mathrm{mmN}$.

The fatigue performance that is obtained before and after optimum SP is illustrated in Figure 9. As seen from Figure 9, compared to the unpeened ZK60 alloy, the improvement of $7 \%$ in fatigue strength (from 140 to $150 \mathrm{MPa}$ ) has been achieved by T5 aging treatment. Fatigue life of the ZK60-T5 


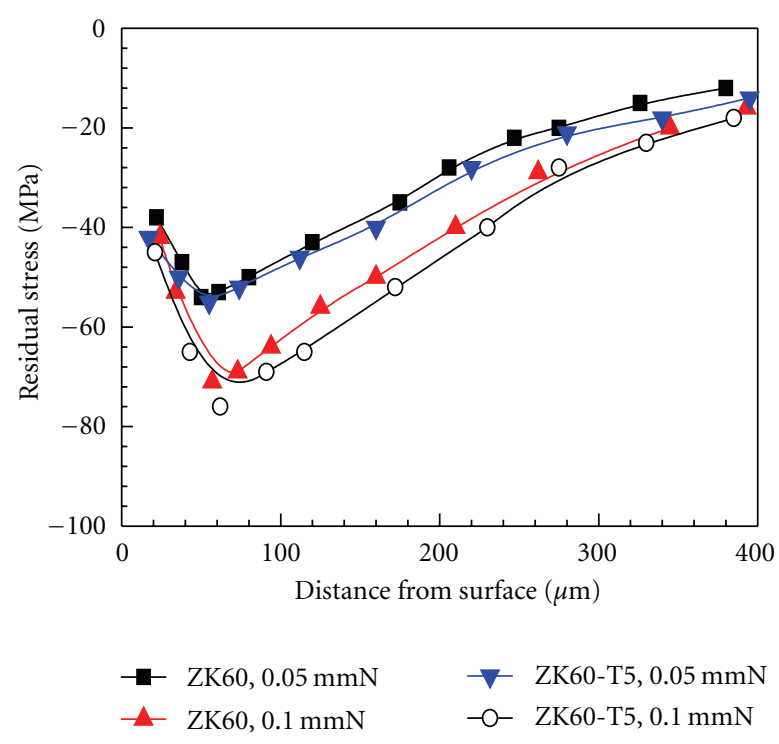

(a)

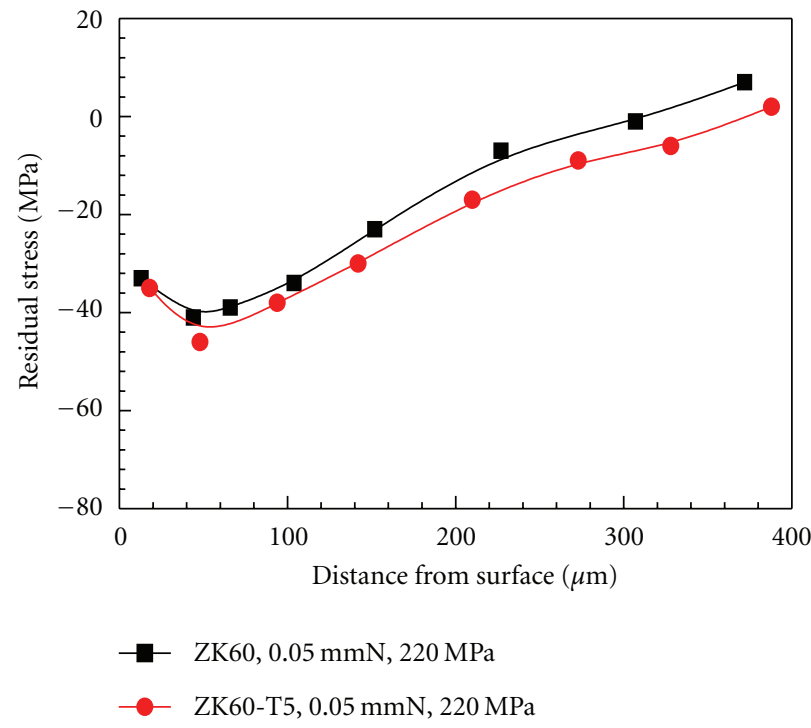

(b)

FIGURE 7: (a) Residual stress-depth profile of the peened specimens, and (b) residual stress relaxation of the specimens after the optimum SP and fatigue test.

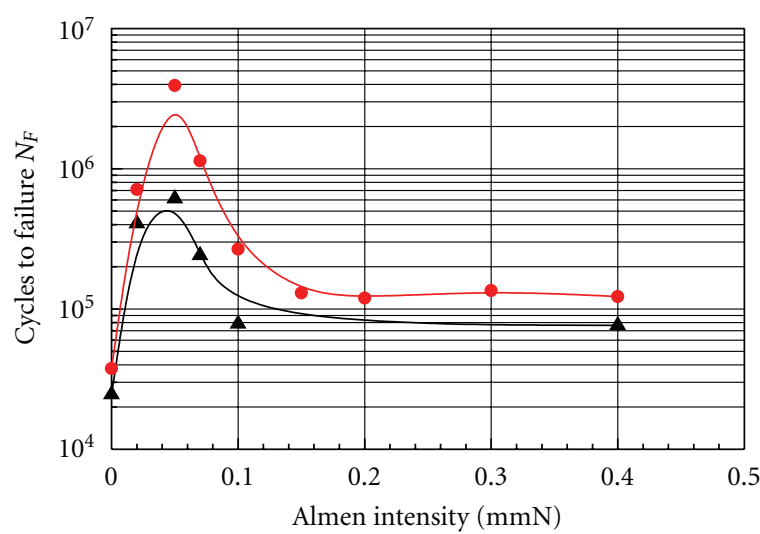

$\leftarrow \sigma_{a}=200 \mathrm{MPa}$

$\rightarrow \sigma_{a}=185 \mathrm{MPa}$

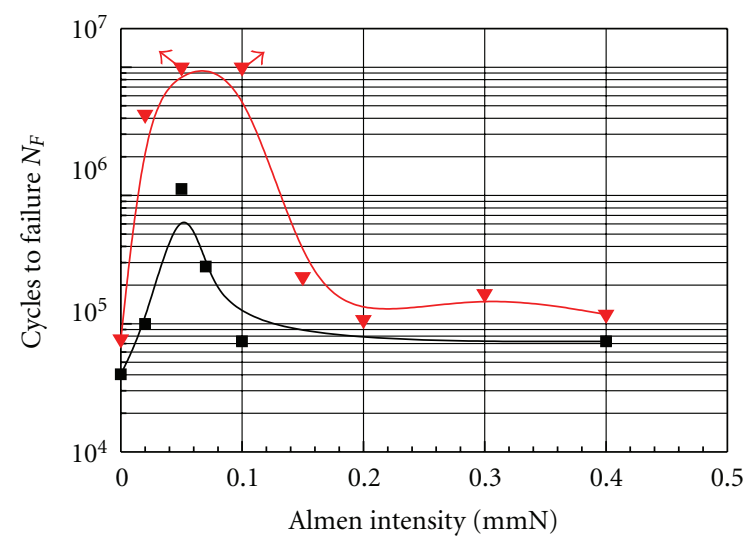

$\rightarrow \sigma_{a}=200 \mathrm{MPa}$

$\rightarrow \sigma_{a}=185 \mathrm{MPa}$

(a)

(b)

Figure 8: Fatigue life versus Almen intensity of the (a) ZK60 and (b) ZK60-T5 alloys at different stress amplitudes.

alloy is higher than that of the ZK60 alloy, particularly at the lower stress amplitude. In addition, compared to the reference specimens (EP), the fatigue life is improved by SP at all stress amplitudes. The fatigue strengths (at $10^{7}$ cycles) of the peened ZK60 and ZK60-T5 alloys increased from 140 and $150 \mathrm{MPa}$ to 180 and $195 \mathrm{MP}$, corresponding to the improvements in fatigue strength by SP of about $28 \%$ and $30 \%$, respectively.

3.4. Fractography. Overall fracture surfaces of the ZK60 and ZK60-T5 alloys before and after SP are shown in Figures 10 and 11, respectively. As seen from Figures 10(a), 10(b), 11(a), and 11(b), the fatigue crack in the EP specimens nucleated at the surface, since the surface experienced the maximum tensile stress during rotating beam loading fatigue. Compared to the EP condition, the fatigue crack nucleation site and the peened specimens of the ZK60 and ZK60-T5 alloys under the optimum SP condition shifted to the subsurface regions (see Figures 10(c), 10(d), 11(c), and 11(d)). The crack nucleation site is located in the depth of about 100 $150 \mu \mathrm{m}$ from surface, in agreement with the thickness of the plastic deformation layer estimated from the microhardnessdepth profiles. With an increase in Almen intensity, a significantly higher number of fatigue cracks and crack initiation sites can be seen, and this increase in Almen intensity from 0.02 to $0.40 \mathrm{mmN}$ shifted the fatigue crack initiation site 


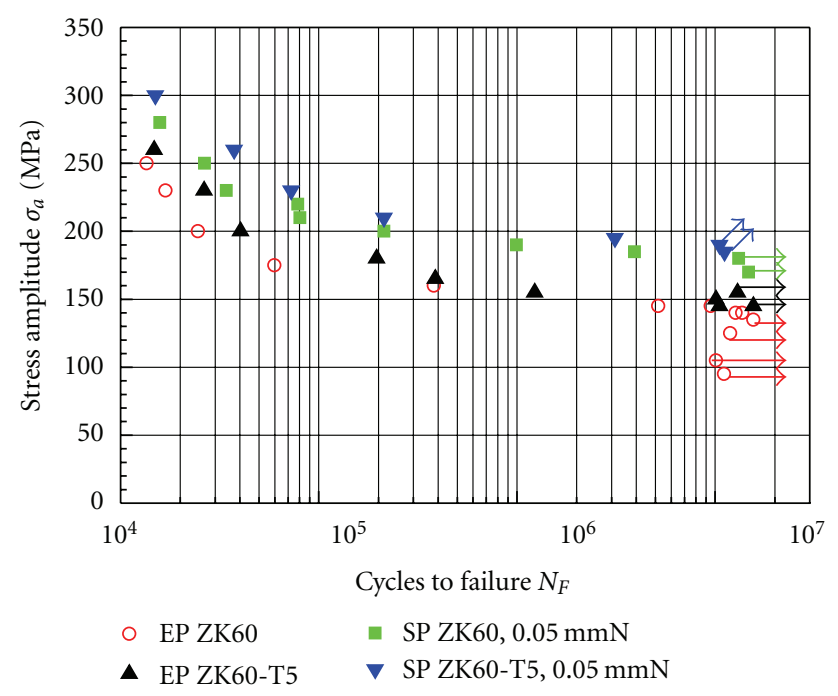

Figure 9: $S$-N curves of the ZK60 and ZK60-T5 alloys before and after the optimum SP.

in the ZK60 and ZK60-T5 alloys from subsurface regions to the surface (see Figures 10(e), 10(f), 11(e), and 11(f)). Presumably, the limited deformability of the hexagonal crystal structure of the magnesium alloy leads to the development of critical microcracks during heavier SP and, thus, to crack growth from the surface into the interior. In addition, numerous secondary cracks which were hindered to propagate were found, particularly on specimens peened to higher intensities (see Figures 10(e), 10(f), 11(e), and 11(f)), indicating a pronounced effect of surface roughness on the resistance to fatigue crack nucleation. However, there is no significant difference in fatigue crack nucleation of EP and peened specimens between the ZK60 and ZK60-T5 alloys.

As reported previously $[16,19,20]$, the fatigue surfaces in both kinds of materials at the EP condition can be subdivided into three distinct regions (see Figures 10(a) and 11(a)): crack initiation region (Region 1), steady crack propagation region (Region 2), and tearing region (Region 3 ). The crack propagation mechanism in each stage has been discussed in the previous papers $[16,20]$. Similarly, the fracture surfaces of the peened specimens can also be subdivided into three stages (see Figures 10(c) and 11(c)). The characteristics of Regions 2 and 3 in the peened specimens were similar to those of the EP specimens and so are not repeated here $[16,18]$.

\section{Discussion}

The fatigue performance of the peened ZK60 and ZK60-T5 alloys depends on the combined effects of surface roughness, strain hardening, and compressive residual stresses produced by SP. The surface roughening accelerates the fatigue crack propagation, while strain hardening retards the propagation of cracks by increasing the resistance to plastic deformation and the compressive residual stress provides a corresponding crack closure stress that reduces the driving force for crack propagation [21-23]. In the present study, the reason for

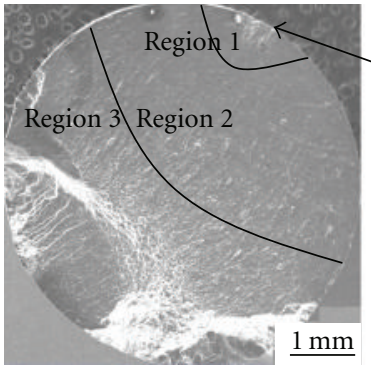

(a)

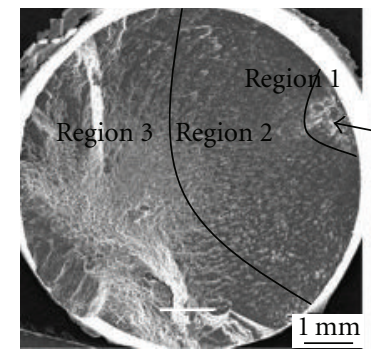

(c)

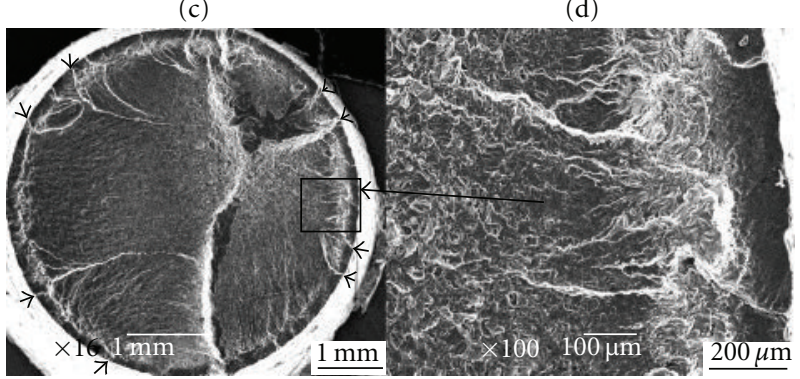

(e)

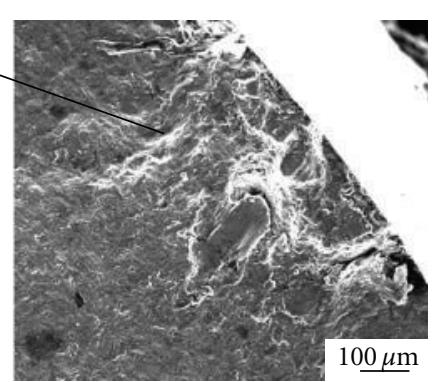

(b)

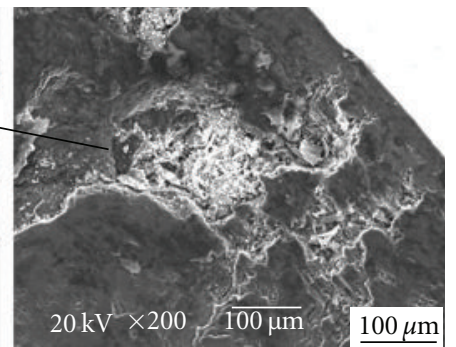

(d)

(f)
FIGURE 10: Fatigue fractures of ZK60 alloy before and after SP: (a) overall fracture surface and (b) crack initiation site, EP, $160 \mathrm{MPa}$; (c) overall fracture surface and (d) crack initiation site, $0.05 \mathrm{mmN}$, $190 \mathrm{MPa}$; (e) overall fracture surface and (f) crack initiation site, $0.40 \mathrm{mmN}, 185 \mathrm{MPa}$.

fatigue life improvement by SP would be attributed to retardation of microcrack growth, as the positive effect on fatigue life induced by the compressive residual stress field is greater than the reduction in fatigue life caused by SPinduced higher surface roughness $[8,24,25]$. As compressive residual stresses introduced into the surface and subsurface layers by SP usually decrease the tensile stress in the component under external forces, fatigue cracks do not easily initiate or propagate; thus, improvements in fatigue strength are achieved. In addition, it is well known that the heavier SP not only results in lower near surface compressive residual stresses but also increases roughness and induces microcracks [8]. For magnesium alloys, due to the limited deformability of HCP crystal structure at room temperature, surface damages are aggravated. At the lower Almen intensities $(0.02-0.10 \mathrm{mmN})$, the life benefit outweighs the debit due to additional surface damages. However, with the increases in Almen intensity $(>0.10 \mathrm{mmN})$, more severe defects such as overlaps and microcracks occur, and the life improvement dramatically decreases; that is, ZK60 magnesium alloy shows a marked overpeening effect. Similar overpeening effects 


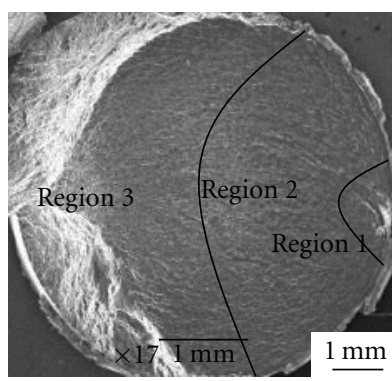

(a)

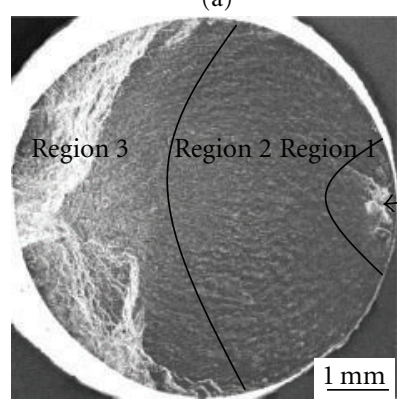

(c)

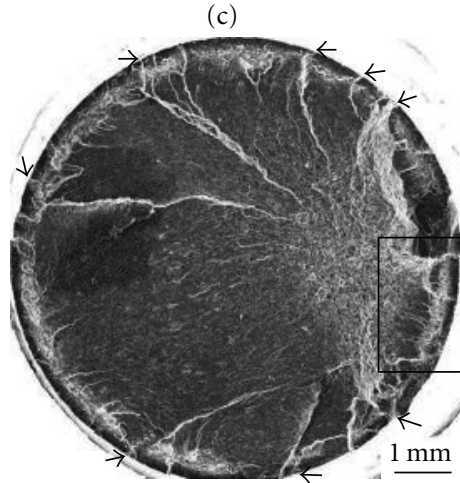

(e)

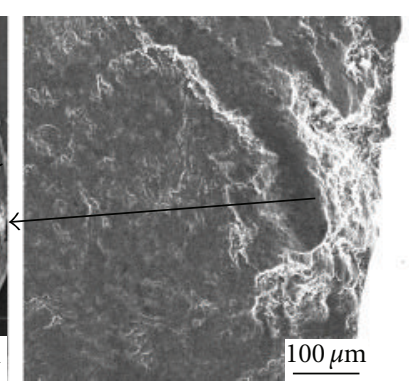

(b)

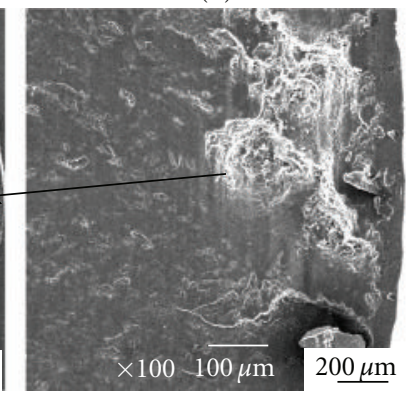

(d)

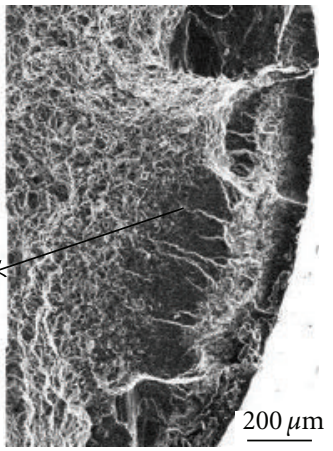

(f)
FIgure 11: Fatigue fractures of ZK60-T5 alloy after SP: (a) overall fracture surface and (b) crack initiation site, EP, $160 \mathrm{MPa}$; (c) overall fracture surface and (d) crack initiation site, $0.05 \mathrm{mmN}, 200 \mathrm{MPa}$; (e) overall fracture surface and (f) crack initiation site, $0.30 \mathrm{mmN}$, $185 \mathrm{MPa}$.

have also been observed in various materials by other researchers $[7,8,26,27]$.

In addition, the fatigue performance improvement of the ZK60-T5 alloy by SP is slightly superior to that of the ZK60 alloy; the mechanism is as follows: (a) the $\beta^{\prime}(\mathrm{MgZn})$ phase in the ZK60-T5 alloy is beneficial to the dislocation tangle and dislocation accumulation during SP, compared to the ZK60 alloy. In this work, actual dislocation density was not measured. But it is believed that the density of dislocations and twins in the ZK60-T5 alloy are higher than those in the ZK60 alloy. Therefore, the $\beta^{\prime}(\mathrm{MgZn})$ phase, dislocations, and twins in the ZK60-T5 alloy acted as barriers to dislocation motion and fatigue crack growth; (b) stability of work hardening is desirable for fatigue life enhancement, especially in smooth, soft, and mechanically surface-treated materials such as peened magnesium alloys since the effectiveness of SP is governed by the stability of near-surface work hardening
[28]. Comparatively, the compressive residual stress of the peened ZK60 alloy relaxed slightly more rapidly than in the peened ZK60-T5 alloy during fatigue cycles leading to lower fatigue lives (see Figure 7). The above factors result in that the fatigue strength improvement (45 MPa) of the ZK60-T5 alloy is slightly higher than that of the ZK60 alloy (40 MPa). However, the mechanism about different residual stress relaxation rate during fatigue between ZK60 and ZK60-T5 alloys is still not clear, which will be the next study.

\section{Conclusions}

The influence of SP on high cycle fatigue performance of the ZK60 and ZK60-T5 alloys was investigated. The major conclusions can be made as follows.

(i) SP improved fatigue strength of the ZK60 and ZK60T5 alloys significantly, and the effect of SP in the ZK60-T5 alloy is slightly superior to that in the ZK60 alloy. The fatigue strengths (at $10^{7}$ cycles) of the ZK60 and ZK60-T5 alloys after SP at the optimum Almen intensity of $0.05 \mathrm{mmN}$ increased from 140 and $150 \mathrm{MPa}$ to 180 and $195 \mathrm{MP}$, corresponding to the improvements in fatigue strength of about $28 \%$ and $30 \%$, respectively.

(ii) Fatigue cracks in the EP specimens for the ZK60 and ZK60-T5 alloys nucleated at the surface. After SP with low Almen intensity $(<0.15 \mathrm{mmN})$, the compressive residual stress in plastic deformation layer produced by SP transfers the fatigue crack nucleation site from surface to the subsurface. With an increase in Almen intensity, a significantly higher number of fatigue crack nucleation sites as well as surface crack initiation can be seen.

(iii) A pronounced overpeening effect is observed in ZK60-T5. The fatigue life first dramatically increases with the increase of Almen intensity compared to an unpeened specimen and then drastically drops as the intensity further increased. This overpeening effect is associated with the limited deformability of the hexagonal crystal structure of magnesium at room temperature.

(iv) The present results demonstrate that SP is an effective method to improve fatigue performance of the ZK60 alloy.

\section{Acknowledgments}

This project is sponsored by the National Natural Science Foundation of China (no. 50901045) and Shanghai RisingStar Program (A type, 09QA1403100).

\section{References}

[1] A. Luo and M. O. Pekguleryuz, "Cast magnesium alloys for elevated temperature applications," Journal of Materials Science, vol. 29, no. 20, pp. 5259-5271, 1994. 
[2] B. L. Mordike and T. Ebert, "Magnesium properties-applications-potential," Materials Science and Engineering A, vol. 302, no. 1, pp. 37-45, 2001.

[3] A. Eliezer, E. M. Gutman, E. Abramov, and Y. Unigovski, "Corrosion fatigue of die-cast and extruded magnesium alloys," Journal of Light Metals, vol. 1, no. 3, pp. 179-186, 2001.

[4] T. S. Shih, W. S. Liu, and Y. J. Chen, "Fatigue of as-extruded AZ61A magnesium alloy," Materials Science and Engineering A, vol. 325, no. 1-2, pp. 152-162, 2002.

[5] S. Tekeli, "Enhancement of fatigue strength of SAE 9245 steel by shot peening," Materials Letters, vol. 57, no. 3, pp. 604-608, 2002.

[6] M. A. S. Torres and H. J. C. Voorwald, "An evaluation of shot peening, residual stress and stress relaxation on the fatigue life of AISI 4340 steel," International Journal of Fatigue, vol. 24, no. 8, pp. 877-886, 2002.

[7] P. Zhang and J. Lindemann, "Influence of shot peening on high cycle fatigue properties of the high-strength wrought magnesium alloy AZ80," Scripta Materialia, vol. 52, no. 6, pp. 485-490, 2005.

[8] L. Wagner, "Mechanical surface treatments on titanium, aluminum and magnesium alloys," Materials Science and Engineering A, vol. 263, no. 2, pp. 210-216, 1999.

[9] N. Barry, S. V. Hainsworth, and M. E. Fitzpatrick, "Effect of shot peening on the fatigue behaviour of cast magnesium A8," Materials Science and Engineering A, vol. 507, no. 1-2, pp. 5057, 2009.

[10] H. T. Zhou, Z. D. Zhang, C. M. Liu, and Q. W. Wang, "Effect of $\mathrm{Nd}$ and $\mathrm{Y}$ on the microstructure and mechanical properties of ZK60 alloy," Materials Science and Engineering A, vol. 445-446, pp. 1-6, 2007.

[11] R. B. Figueiredo and T. G. Langdon, "Principles of grain refinement and superplastic flow in magnesium alloys processed by ECAP," Materials Science and Engineering A, vol. 501, no. 1-2, pp. 105-114, 2009.

[12] R. Lapovok, P. F. Thomson, R. Cottam, and Y. Estrin, "Processing routes leading to superplastic behaviour of magnesium alloy ZK60," Materials Science and Engineering A, vol. 410-411, pp. 390-393, 2005.

[13] C. Y. Wang, K. Wu, and M. Y. Zheng, "Hot deformation behavior of Al18B4O33w/ZK60 magnesium matrix composite," Materials Science and Engineering A, vol. 487, no. 1-2, pp. 495-498, 2008.

[14] J. E. Gray and B. Luan, "Protective coatings on magnesium and its alloys-a critical review," Journal of Alloys and Compounds, vol. 336, no. 1-2, pp. 88-113, 2002.

[15] Y. Unigovski, A. Eliezer, E. Abramov, Y. Snir, and E. M. Gutman, "Corrosion fatigue of extruded magnesium alloys," Materials Science and Engineering A, vol. 360, no. 1-2, pp. 132 139, 2003.

[16] W. C. Liu, J. Dong, P. Zhang, Z. Y. Yao, C. Q. Zhai, and W. J. Ding, "High cycle fatigue behavior of as-extruded ZK60 magnesium alloy," Journal of Materials Science, vol. 44, no. 11, pp. 2916-2924, 2009.

[17] W. C. Liu, J. Dong, X. W. Zheng, P. Zhang, and W. J. Ding, "Influence of shot peening on notched fatigue properties of magnesium alloy ZK60," Materials Science and Technology, vol. 27, no. 1, pp. 201-207, 2011.

[18] W. C. Liu, J. Dong, P. Zhang, C. Q. Zhai, and W. J. Ding, "Effect of shot peening on surface characteristics and fatigue properties of T5-treated ZK60 alloy," Materials Transactions, vol. 50, no. 4, pp. 791-798, 2009.

[19] W. C. Liu, J. Dong, P. Zhang et al., "Fatigue behavior of hotextruded Mg-10Gd-3Y magnesium alloy," Journal of Materials Research, vol. 25, no. 4, pp. 773-783, 2010.
[20] J. Dong, W. C. Liu, X. Song, P. Zhang, W. J. Ding, and A. M. Korsunsky, "Influence of heat treatment on fatigue behaviour of high-strength Mg-10Gd-3Y alloy," Materials Science and Engineering A, vol. 527, no. 21-22, pp. 6053-6063, 2010.

[21] S. Curtis, E. R. de los Rios, C. A. Rodopoulos, and A. Levers, "Analysis of the effects of controlled shot peening on fatigue damage of high strength aluminium alloys," International Journal of Fatigue, vol. 25, no. 1, pp. 59-66, 2002.

[22] B. R. Sridhar, K. Ramachandra, and K. A. Padmanabhan, "Effect of shot peening on the fatigue and fracture behaviour of two titanium alloys," Journal of Materials Science, vol. 31, no. 22, pp. 5953-5960, 1996.

[23] O. Hatamleh, "A comprehensive investigation on the effects of laser and shot peening on fatigue crack growth in friction stir welded AA 2195 joints," International Journal of Fatigue, vol. 31, no. 5, pp. 974-988, 2009.

[24] N. Tsuji, S. Tanaka, and T. Takasugi, "Effects of combined plasma-carburizing and shot-peening on fatigue and wear properties of Ti-6Al-4V alloy," Surface and Coatings Technology, vol. 203, no. 10-11, pp. 1400-1405, 2009.

[25] J. Lindemann, C. Buque, and F. Appel, "Effect of shot peening on fatigue performance of a lamellar titanium aluminide alloy," Acta Materialia, vol. 54, no. 4, pp. 1155-1164, 2006.

[26] M. Larsson, A. Melander, R. Blom, and S. Preston, "Effects of shot peening on bending fatigue strength of spring steel SS 2090," Materials Science and Technology, vol. 7, no. 11, pp. 9981004, 1991.

[27] R. A. Chernenkoff, S. Mocarski, and D. A. Yeager, "Increased fatigue strength of powder forged connecting rods by optimised shot peening," Powder Metallurgy, vol. 38, no. 3, pp. 196-200, 1995.

[28] P. Juijerm, I. Altenberger, and B. Scholtes, "Fatigue and residual stress relaxation of deep rolled differently aged aluminium alloy AA6110," Materials Science and Engineering A, vol. 426, no. 1-2, pp. 4-10, 2006. 

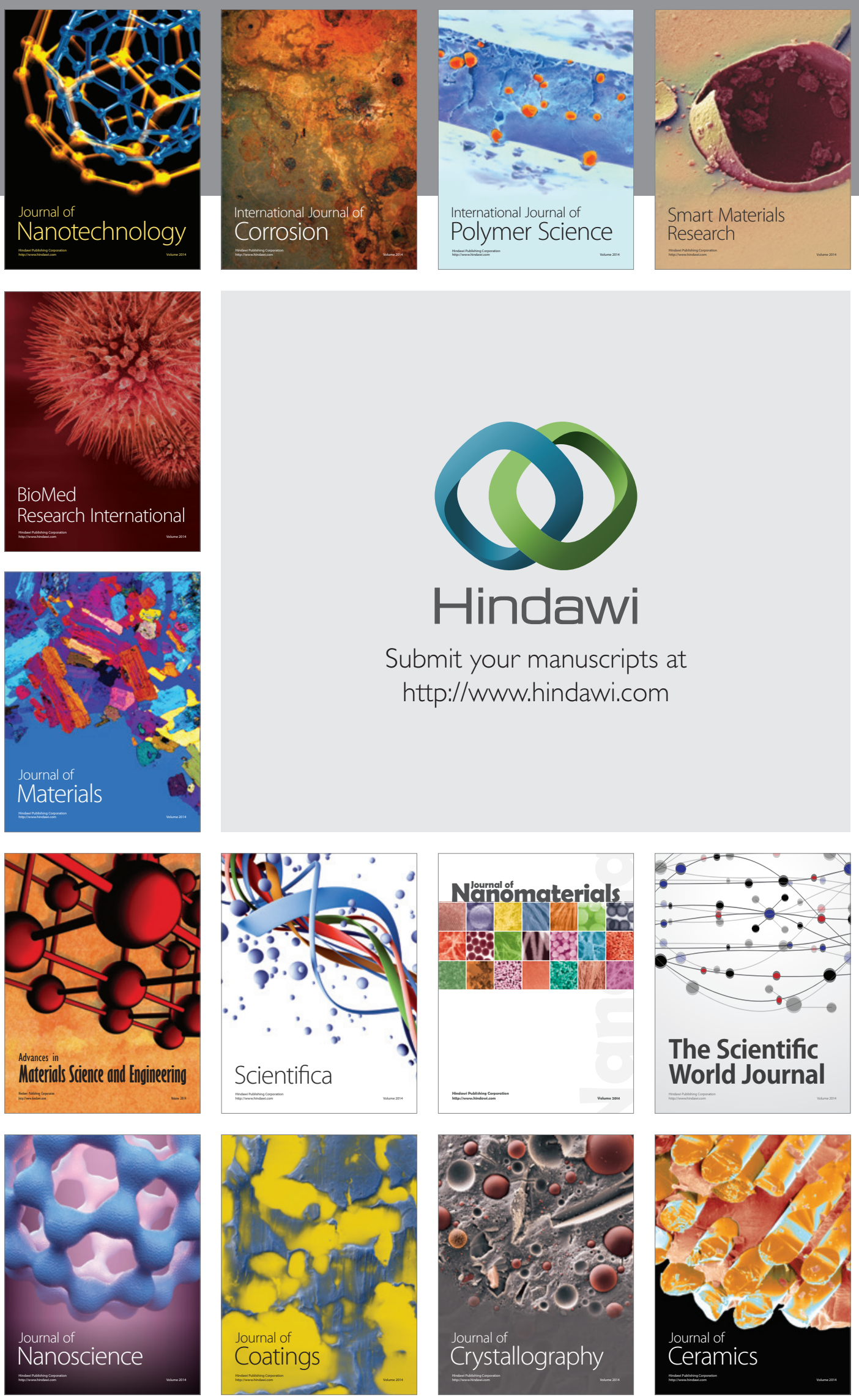

The Scientific World Journal

Submit your manuscripts at

http://www.hindawi.com

\section{World Journal}

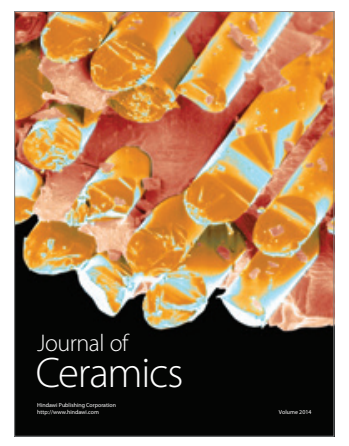

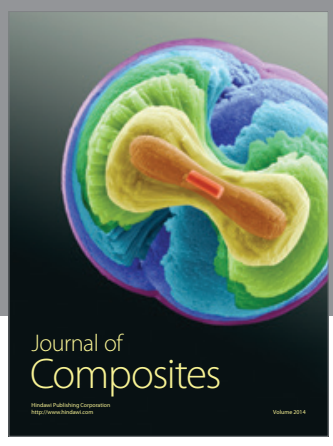
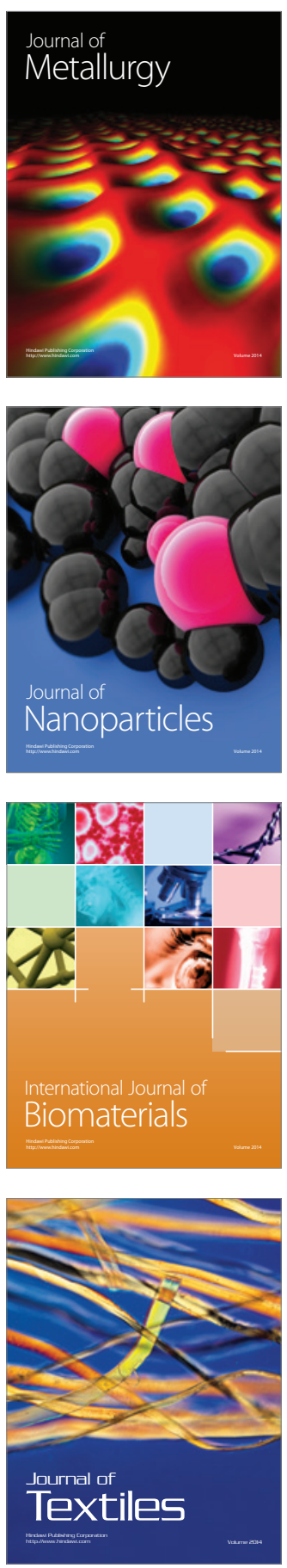